\title{
Correlates of prolonged television viewing time in older Japanese men and women
}

\author{
Hiroyuki Kikuchi ${ }^{*}$, Shigeru Inoue ${ }^{1}$, Takemi Sugiyama ${ }^{2}$, Neville Owen ${ }^{2,45,6}$, Koichiro Oka $^{3}$ and Teruichi Shimomitsu ${ }^{1}$
}

\begin{abstract}
Background: In addition to insufficient moderate-to-vigorous physical activity (MVPA), prolonged sitting time is also a health risk for older adults. An understanding of population subgroups who have prolonged television viewing (TV) time, a predominant sedentary behavior, can aid in the development of relevant health promotion initiatives; however, few such studies have focused on older adults, the most sedentary segment of the population as a whole. The aim of this study is to examine the socio-demographic attributes associated with TV time among community-dwelling Japanese older men and women.
\end{abstract}

Methods: A population-based, cross-sectional mail survey was used to collect data on TV time, MVPA, and sociodemographic characteristics. The survey was conducted from February through March 2010. Participants were 2700 community-dwelling older adults (aged 65-74 years, 50\% men) who were randomly selected from the registry of residential addresses of three cities in Japan. Data from 1665 participants (mean age: 69.5 years, 52\% men) who completed all variables for the present study were analyzed. Multivariate logistic regression analyses were used to calculate the odds ratios (ORs) of prolonged TV time ( $>2$ hours/day) for each socio-demographic attribute, stratified by gender.

Results: Of the 1665 participants, 810 (48.6\%) watched TV for more than 2 hours/day. The median television viewing time $(25$ th, 75 th percentile) was $2.00(1.07,3.50)$ hours/day. Prolonged TV time was associated with not in full-time employment, lower educational attainment, weight status, living in regional areas and low MVPA for the whole sample. For men, prolonged TV time was associated with lower educational attainment; ( $\mathrm{OR}=1.53,95 \% \mathrm{Cl}$ : 1.12-2.07), underweight $(\mathrm{OR}=1.63,95 \% \mathrm{Cl}: 1.02-2.60)$, overweight $(\mathrm{OR}=1.57,95 \% \mathrm{Cl}: 1.11-2.21)$, and low MVPA $(\mathrm{OR}=1.43,95 \% \mathrm{Cl}$ : 1.02-2.02). For women, living in regional areas $(\mathrm{OR}=2.02,95 \% \mathrm{Cl}: 1.33-3.08)$, living alone $(\mathrm{OR}=1.61,95 \% \mathrm{Cl}: 1.03-2.49)$, not driving $(\mathrm{OR}=1.79,95 \% \mathrm{Cl} 1.21-2.65)$, overweight $(\mathrm{OR}=1.50,95 \% \mathrm{Cl}: 1.00-2.24)$, and low MVPA (OR $=1.51 .95 \% \mathrm{Cl}: 1.05-2.17)$ were associated with prolonged TV time.

Conclusions: These findings identify particular socio-demographic and behavioral characteristics related to TV time among Japanese older adults. It should be noted that correlates of prolonged TV time differed by gender. Women in living situations with limited transportation options tended to spend prolonged time watching TV. Health promotion initiatives for older adults, particularly for older women, may be more effective if they take these attributes into account.

Keywords: Sedentary behavior, Socio-demographic attributes, Population-based study, Cross-sectional study

\footnotetext{
* Correspondence: kikuchih@tokyo-med.ac.jp

'Department of Preventive Medicine and Public Health, Tokyo Medical

University, Tokyo, Japan

Full list of author information is available at the end of the article
} 


\section{Background}

Sedentary behaviors, which are distinct from lack of moderate-to-vigorous physical activity (MVPA), are associated with increased cardio-metabolic risk [1]. Studies have shown relationships between prolonged sitting and poor health outcomes independent of physical activity levels [2]. Television viewing (TV), a predominant sedentary behavior during leisure time, has an association with obesity and cardiovascular disease [3], atherosclerosis [4], the metabolic syndrome [5,6], and poor mental health [7]. Several longitudinal studies have found that prolonged TV time increases risk of type 2 diabetes [8] as well as all-cause and cardiovascular mortality [9]. Decreasing sedentary behavior, in addition to increasing physical activity, is now considered an important strategy to reduce health risk $[10,11]$.

Older adults are the most sedentary segment of the population, potentially due to increased leisure time availability following retirement and declining functional capabilities [12,13]. TV viewing is a common leisure-time sedentary behavior among older adults [14], and older adults' TV time can be associated with the prevalence of metabolic syndrome [15,16] and obesity [17]. However, little is known about which subgroups of older adults spend more time watching TV [15]. Such information is important in identifying specific population groups in need of future interventions. In the light of existing studies that show gender differences in demographic and behavioral correlates of sedentary behavior [14,18-20], we examined attributes associated with prolonged TV time among community-dwelling older men and women in Japan.

\section{Methods}

\section{Participants and data collection}

The study sample was recruited from 2700 community residents, from ages 65 to 74 years, living in three Japanese municipalities; Bunkyo Ward in Tokyo, Fuchu City in Tokyo, and Oyama Town in Shizuoka Prefecture (Figure 1). Bunkyo lies at the center of Tokyo (area: $11.3 \mathrm{~km}^{2}$, population: 191,463). Fuchu is a suburban city within the Tokyo Metropolitan Area located about $20 \mathrm{~km}$ east of the center of Tokyo (area: $29.3 \mathrm{~km}^{2}$, population: 244,834 ). Oyama is a small regional town, located about $80 \mathrm{~km}$ east of Tokyo (area: $136.1 \mathrm{~km}^{2}$, population: 20,783). In Japan, regional towns are typically less than 50,000 in population, and not in the vicinity of larger cities, such as a prefecture's capital city. The sample was randomly selected from the registry of residential addresses of each municipality, stratified by gender (men, women), age (6569 years, 70-74 years), and municipalities of residence (Bunkyo, Fuchu, Oyama); 1350 residents of each gender, 1350 residents of each age category, and 900 residents from each locality were identified. Data were collected from February to March 2010.

Potential participants received invitation letters that described the study. Two weeks after the invitation, they received a questionnaire and consent form. During the survey, a call center was set up to answer participants'

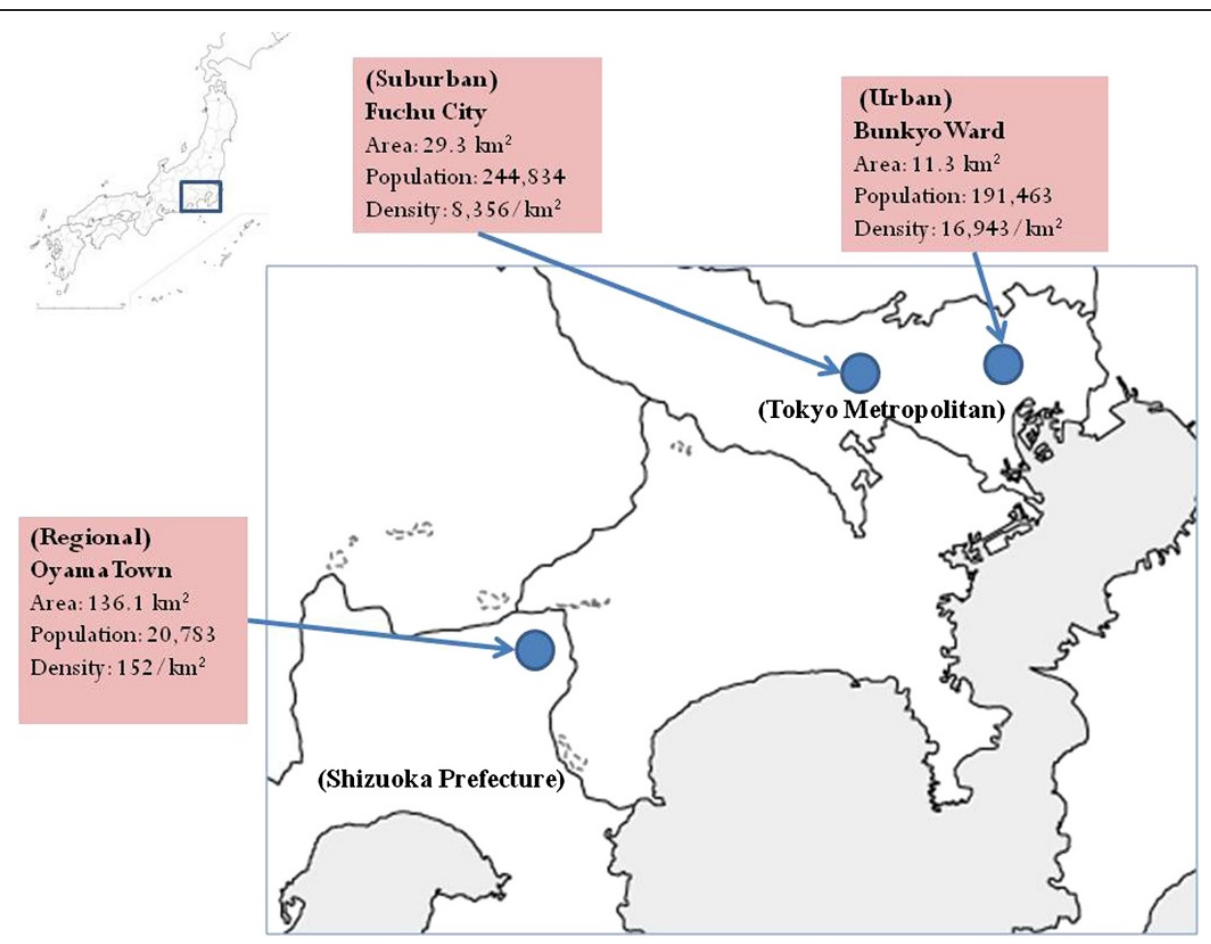

Figure 1 Location and characteristics of the three Japanese cities from which residents were recruited. 
inquiries. To encourage participation, a 500-yen (about 5.5 U.S. dollars in 2010) book voucher was offered to respondents. For non-respondents, reminders to return the survey were mailed twice. Those who sent an incomplete survey were asked to complete the survey.

Of the 2700 initially identified, 2046 returned the survey. After data cleaning, the data from 1816 participants were deemed valid for this study (response rate: 67.3\%). Among these respondents, 151 participants who had difficulty performing daily activities assessed by the Japanese 8-item Short-Form Health Survey (SF-8) [21] were excluded from the present analyses. The final sample size was 1665 .

Participants signed an informed consent document before answering the questionnaire. This study received prior approval from the Tokyo Medical University Ethics Committee.

\section{Measures}

\section{Dependent variable}

TV time was determined by participants' self-reported frequency of watching television or videos (days/week) and average viewing duration per day (minutes/day) over the past 7 days. This question was translated into Japanese from an Australian questionnaire on leisure-time sedentary behaviors. The test-retest reliability of this questionnaire was reported as 0.82 [22]. In addition, significant associations with a three-day log (validity) were also reported [22]. Television viewing time is the particular sedentary behavior for which there is the strongest evidence of reliability and validity [23]. TV time was dichotomized based on the median value into two categories; short $[\leq 2$ hours/day] and long [ $>2$ hours/day]. This cut point ( $>2$ hours/day) was also reported as health risks in previous studies $[5,24]$.

\section{Independent variables}

Age, gender and municipality of residence were obtained from the registry of residential addresses of each municipality. Living arrangements (living with others or living alone), educational attainment (years of education), employment status (working hours per week), self-rated health, dog ownership (having a dog, or not), driving status (driver, or non-driver), MVPA (minutes per week), body weight and height were obtained through self-report by each respondent. Self-rated health was assessed using an item from the SF-8: "Overall, how would you rate your health during the past 4 weeks?" Participants responded to the statement using a 6-point scale consisting of "excellent", "very good", "good", "fair", "poor", and "very poor" [21]. For MVPA, the Japanese version of the International Physical Activity Questionnaire Short-version was used [25]. Participants were asked to report the frequency and duration of three types of physical activity: vigorousintensity, moderate-intensity (excluding walking), and walking. Total time spent in MVPA including walking was calculated by adding these three activities together.

\section{Statistical analyses}

Multivariate logistic regressions were employed to calculate odd ratios (ORs) and 95\% confidence intervals (95\% CI) of prolonged TV time (more than 2 hours per day) according to socio-demographic and individual variables. Physical activity was classified by tertiles: "low $[<200 \mathrm{~min} /$ week], "medium [200-509 min/week]" and "high [ $\geq 510 \mathrm{~min} /$ week]". This classification was used because a large proportion of participants (about 75\%) reported $150 \mathrm{~min} /$ week or more MVPA, the current recommendation for older adults. Demographic variables were categorized as below; age ("65 to 69" or "70 to 74 years"), years of education ("up to high school $[<13$ years]" or "college degree or more [ $\geq 13$ years]"), working hours ("none or part-time work [ $<35$ hours/week]", or "full-time work [ $\geq 35$ hours/week]"), and self-rated health ("good" [excellent, very good, or good] or "poor" [fair, poor, or very poor]). Body mass index (BMI) was calculated from self-reported weight and height, and categorized into three categories; underweight $\left(<20 \mathrm{~kg} / \mathrm{m}^{2}\right)$, normal weight $\left(20-24.9 \mathrm{~kg} / \mathrm{m}^{2}\right)$, and overweight $\left(\geq 25 \mathrm{~kg} / \mathrm{m}^{2}\right)$.

Analyses were conducted first for the overall sample, and then separately for men and women, adjusting for the demographic variables, MVPA, self-rated health, and BMI. All statistical analyses were performed using STATA software (version 10); the level of significance was set at $\mathrm{p}<0.05$.

\section{Results}

Table 1 shows the characteristics of the participants. Men accounted for $52.0 \%$ of the respondents. The mean age of participants was 69.5 (sd: 3.0) years for men and 69.6 (sd: 2.9) years for women. The sample included about the same number of participants from each municipalities. The median TV time (25th, 75th percentile) was $2.00(1.07,3.50)$ hours/day overall, $2.00(1.07,3.46)$ hours/day in men and $2.00(1.07,3.50)$ hours/day in women, respectively.

Table 2 shows the results of multivariate logistic regression analyses. For the whole sample; living in regional town, lower educational attainment, not in full-time employment ( $\geq 35$ hours per week), underweight, overweight, and low MVPA ( $<200 \mathrm{~min} /$ week) were associated with longer TV time. In gender-specific analyses, men with lower educational attainment, not in full-time employment, underweight, overweight and low MVPA tended to watch TV longer. Among women, living in regional town, living alone, not in full-time employment, overweight, being a non-driver, and low MVPA were associated with prolonged TV time. 
Table 1 Characteristics of study participants

\begin{tabular}{|c|c|c|c|c|c|c|}
\hline & \multicolumn{2}{|c|}{ Total $(n=1665)$} & \multicolumn{2}{|c|}{ Men $(n=865)$} & \multicolumn{2}{|c|}{ Women $(n=800)$} \\
\hline & $n$ & $(\%)$ & $\mathrm{n}$ & $(\%)$ & $n$ & (\%) \\
\hline \multicolumn{7}{|l|}{ Age group (years) } \\
\hline $65-69$ & 827 & $(49.7)$ & 430 & $(49.7)$ & 397 & (49.6) \\
\hline $70-74$ & 838 & $(50.3)$ & 435 & $(50.3)$ & 403 & $(50.4)$ \\
\hline \multicolumn{7}{|l|}{ Municipality } \\
\hline Bunkyo (Urban) & 540 & $(32.4)$ & 283 & $(32.7)$ & 257 & $(32.1)$ \\
\hline Fuchu (Suburban) & 567 & (34.1) & 300 & $(34.7)$ & 267 & (33.4) \\
\hline Oyama (Regional) & 558 & $(33.5)$ & 282 & $(32.6)$ & 276 & (34.5) \\
\hline \multicolumn{7}{|l|}{ Living arrangements } \\
\hline Living with others & 1479 & $(88.8)$ & 782 & $(90.4)$ & 697 & $(87.1)$ \\
\hline Living alone & 186 & $(11.2)$ & 83 & (9.6) & 103 & (12.9) \\
\hline \multicolumn{7}{|c|}{ Educational attainment (education years) } \\
\hline College degree or more $(\geq 13)$ & 606 & $(36.4)$ & 389 & $(45.0)$ & 217 & $(27.1)$ \\
\hline Up to high school $(<13)$ & 1059 & $(63.6)$ & 476 & $(55.0)$ & 583 & $(72.9)$ \\
\hline \multicolumn{7}{|c|}{ Employment status (working hours/week) } \\
\hline Full-time work ( $\geq 35$ ) & 674 & $(40.5)$ & 432 & $(49.9)$ & 242 & (30.3) \\
\hline None or part-time work $(<35)$ & 991 & $(59.5)$ & 433 & $(50.1)$ & 558 & (69.8) \\
\hline \multicolumn{7}{|l|}{ BMI $\left(\mathrm{kg} / \mathrm{m}^{2}\right)$} \\
\hline$<20.0$ & 289 & $(17.4)$ & 91 & $(10.5)$ & 198 & $(24.8)$ \\
\hline $20.0-24.9$ & 1040 & $(62.5)$ & 577 & $(66.7)$ & 463 & $(57.9)$ \\
\hline$\geq 25.0$ & 336 & $(20.2)$ & 197 & $(22.8)$ & 139 & $(17.4)$ \\
\hline \multicolumn{7}{|l|}{ Self-rated health } \\
\hline Good & 1401 & $(84.1)$ & 734 & $(84.9)$ & 667 & (83.4) \\
\hline Poor & 264 & $(15.9)$ & 131 & $(15.1)$ & 133 & (16.6) \\
\hline \multicolumn{7}{|l|}{ Dog ownership } \\
\hline Yes & 231 & $(13.9)$ & 128 & $(14.8)$ & 103 & (12.9) \\
\hline No & 1434 & $(86.1)$ & 737 & $(85.2)$ & 697 & $(87.1)$ \\
\hline \multicolumn{7}{|l|}{ Driving status } \\
\hline Yes & 717 & $(43.1)$ & 523 & $(60.5)$ & 194 & (24.3) \\
\hline No & 948 & $(56.9)$ & 342 & $(39.5)$ & 606 & (75.8) \\
\hline \multicolumn{7}{|l|}{ MVPA (minutes/week) } \\
\hline$<200$ & 549 & (33.0) & 266 & $(30.8)$ & 283 & $(35.4)$ \\
\hline $200-509$ & 544 & $(32.7)$ & 272 & $(31.4)$ & 272 & $(34.0)$ \\
\hline$\geq 510$ & 572 & $(34.4)$ & 327 & $(37.8)$ & 245 & (30.6) \\
\hline \multicolumn{7}{|l|}{ TV viewing(hours/day) } \\
\hline$\leq 2$ & 855 & $(51.4)$ & 457 & $(52.8)$ & 398 & $(49.8)$ \\
\hline$>2$ & 810 & $(48.6)$ & 408 & $(47.2)$ & 402 & $(50.3)$ \\
\hline
\end{tabular}

BMI: body mass index, MVPA: moderate to vigorous physical activity.

\section{Discussion}

The characteristics associated with prolonged TV viewing time (two or more hours a day) among older Japanese adults were: regional residence, living alone, lower educational attainment, not in full-time employment, underweight, overweight, and low MVPA. Older men and women differed in their correlates of prolonged TV time.
The common correlates for men and women were: not in full-time employment, overweight, and low MVPA. As expected, prolonged TV time was more prevalent among older adults who were not in full-time employment and who presumably had more available leisure time. The lifestyle transitions associated with of retirement may be influential in this context. In previous 
Table 2 Correlates of prolonged TV time by gender

\begin{tabular}{|c|c|c|c|c|c|c|c|c|c|}
\hline & \multicolumn{3}{|c|}{ Total } & \multicolumn{3}{|c|}{ Men } & \multicolumn{3}{|c|}{ Women } \\
\hline & OR & $(95 \% \mathrm{Cl})$ & $p$ & OR & $(95 \% \mathrm{Cl})$ & $p$ & OR & $(95 \% \mathrm{Cl})$ & $p$ \\
\hline \multicolumn{10}{|l|}{ Gender } \\
\hline Women & 1.00 & & & & & & & & \\
\hline Men & 1.21 & $(0.97-1.52)$ & 0.098 & & & & & & \\
\hline \multicolumn{10}{|l|}{ Age group (years) } \\
\hline $65-69$ & 1.00 & & & 1.00 & & & 1.00 & & \\
\hline $70-74$ & 0.89 & $(0.72-1.09)$ & 0.257 & 0.96 & $(0.72-1.27)$ & 0.764 & 0.81 & $(0.60-1.09)$ & 0.164 \\
\hline \multicolumn{10}{|l|}{ Municipality } \\
\hline Bunkyo (Urban) & 1.00 & & & 1.00 & & & 1.00 & & \\
\hline Fuchu (Suburban) & 0.96 & $(0.75-1.23)$ & 0.724 & 0.84 & $(0.59-1.20)$ & 0.348 & 1.05 & $(0.73-1.49)$ & 0.802 \\
\hline Oyama (Regional) & 1.48 & $(1.11-1.97)$ & 0.008 & 1.08 & $(0.72-1.63)$ & 0.715 & 2.02 & $(1.33-3.08)$ & 0.001 \\
\hline \multicolumn{10}{|l|}{ Living arrangements } \\
\hline Living with others & 1.00 & & & 1.00 & & & 1.00 & & \\
\hline Living alone & 1.26 & $(0.92-1.73)$ & 0.156 & 1.01 & $(0.63-1.63)$ & 0.963 & 1.61 & $(1.03-2.49)$ & 0.035 \\
\hline \multicolumn{10}{|c|}{ Educational attainment (education years) } \\
\hline College degree or more $(\geq 13)$ & 1.00 & & & 1.00 & & & 1.00 & & \\
\hline Up to high school $(<13)$ & 1.37 & $(1.09-1.71)$ & 0.006 & 1.53 & $(1.12-2.07)$ & 0.007 & 1.24 & $(0.88-1.74)$ & 0.224 \\
\hline \multicolumn{10}{|l|}{ Employment (hours/wk) } \\
\hline Full-time work $(\geq 35)$ & 1.00 & & & 1.00 & & & 1.00 & & \\
\hline None or part-time work $(<35)$ & 1.91 & $(1.54-2.36)$ & $<0.001$ & 2.20 & $(1.64-2.95)$ & $<0.001$ & 1.71 & $(1.24-2.37)$ & 0.001 \\
\hline \multicolumn{10}{|l|}{ BMI $\left(\mathrm{kg} / \mathrm{m}^{2}\right)$} \\
\hline$<20.0$ & 1.35 & $(1.03-1.78)$ & 0.031 & 1.63 & $(1.02-2.60)$ & 0.041 & 1.24 & $(0.87-1.75)$ & 0.228 \\
\hline $20.0-24.9$ & 1.00 & & & 1.00 & & & 1.00 & & \\
\hline$\geq 25.0$ & 1.55 & $(1.20-2.01)$ & 0.001 & 1.57 & $(1.11-2.21)$ & 0.010 & 1.50 & $(1.00-2.24)$ & 0.048 \\
\hline \multicolumn{10}{|l|}{ Self-reported health } \\
\hline Good & 1.00 & & & 1.00 & & & 1.00 & & \\
\hline Poor & 0.93 & $(0.70-1.22)$ & 0.587 & 0.74 & $(0.50-1.10)$ & 0.139 & 1.17 & $(0.79-1.73)$ & 0.445 \\
\hline \multicolumn{10}{|l|}{ Dog ownership } \\
\hline Yes & 1.00 & & & 1.00 & & & 1.00 & & \\
\hline No & 0.95 & $(0.71-1.27)$ & 0.722 & 1.08 & $(0.72-1.60)$ & 0.721 & 0.80 & $(0.51-1.25)$ & 0.318 \\
\hline \multicolumn{10}{|l|}{ Driving status } \\
\hline Yes & 1.00 & & & 1.00 & & & 1.00 & & \\
\hline No & 1.27 & $(0.99-1.61)$ & 0.057 & 1.01 & $(0.74-1.38)$ & 0.959 & 1.79 & $(1.21-2.65)$ & 0.004 \\
\hline \multicolumn{10}{|l|}{ MVPA (min/wk) } \\
\hline$<200$ & 1.46 & $(1.14-1.87)$ & 0.003 & 1.43 & $(1.02-2.02)$ & 0.040 & 1.51 & $(1.05-2.17)$ & 0.028 \\
\hline $200-509$ & 1.24 & $(0.97-1.58)$ & 0.088 & 1.27 & $(0.91-1.78)$ & 0.167 & 1.25 & $(0.87-1.80)$ & 0.223 \\
\hline$\geq 510$ & 1.00 & & & 1.00 & & & 1.00 & & \\
\hline
\end{tabular}

OR: odds ratio, 95\% Cl: 95\% confidence interval, BMI: body mass index, MVPA: moderate to vigorous physical activity.

ORs were calculated by multivariate logistic regression analysis. All variables indicated in the table were included in the model.

studies, retirement, an important and common lifetransition for older adults, has been identified as being associated with significant change in health-related behaviors such as smoking [26], alcohol consumption [27], and MVPA [28]. Retirement may be an important life transition stage in which to implement programs designed to reduce sedentary behaviors among older adults.

Among men, lower educational attainment was associated with prolonged TV time. Earlier studies have reported that educational attainment to have a strong association with various unhealthy behaviors among men, more than 
among women; this has been the case for smoking, alcohol consumption and low MVPA. Those with lower educational attainment may have less leisure-time options that compete with TV viewing.

For women, regional residence, living alone, and nondriving status were significant demographic correlates of prolonged TV time. These contextual factors may be related to the lack of convenient transportation options, which could hinder older women from going out. Since older women are less likely to have driver's licenses in Japan (84\% in older men vs. $40 \%$ in older women) [29], those who live alone may have a limited means of transport, and tend to stay home for a long period. Similarly, those who live in regional areas have limited public transportation networks. For older adults, going outdoors is an important source of physical activity, and is associated with their functional and health status [30]. This study suggests that the lack of access to transport may pose a greater risk to older women's health by hindering them from going outdoors and giving more time to watch TV indoors.

For men and women, being overweight (compared to normal weight) was associated with a higher likelihood of watching TV for a prolonged period. This is consistent with existing studies that have reported associations of prolonged TV viewing and obesity $[31,32]$. For men, there was an association of being underweight with prolonged TV time. Older men who are underweight, who may also be frail, may tend to sit for longer periods watching TV.

Our findings for older adults are consistent with some of the associations that have been observed for the correlates of television viewing time in young to middle-aged adults. This is the case in relation to lower educational attainment $[5,14,24]$, living in a non-metropolitan area [14], overweight $[5,7,24]$, and not being in paid work [14,24,33] being associated with more-prolonged TV time.

Although older age has been found to be associated consistently with TV time in previous studies [34], our findings identified no significant association with age categories. This is possibly due to the narrower age range of study participants. Regarding dog ownership, which was found to be a significant correlate in a previous study among Japanese young to middle aged adults [35], the present findings do not show a clear association. Possibly, those who were younger may have had less leisure time and thus need to sacrifice TV time to walk with their dogs. It may be that among older adults, dog ownership could act to increase MVPA, but may not necessarily decrease sedentary behaviors.

Some limitations and strengths of our study should be considered. First, all data were collected using self-report measures [36]. TV time is relatively accurate compared with other measures of sedentary behaviors [23], but it may have involved reporting bias. Second, a cross-sectional survey does not allow interpretations of the direction of causality. Reverse causality should be considered, especially for some variables such as BMI and self-rated health. Third, the age range of this sample was relatively narrow. The results of this study cannot be generalized to the older population ( $\geq 75$ years). Studies including a wider range of older people are needed. Fourth, a relatively high proportion (75\%) of our study participants reported levels of physical activity that could be classified as sufficient for health benefits. This may represent an over estimate by our participants, or may reflect some form of reporting or socialdesirability bias. While this is a limitation that should be noted, the major focus of our study was not on physical activity per se. Finally, participant's functional capacity was assessed using SF-8, an instrument to assess physical and mental health for adults in general. A more accurate measure of physical functioning is needed in future research. The strengths of this study include randomly-selected study participants from three different localities (urban, suburban, and regional).

\section{Conclusions}

Prolonged TV time was associated with regional place of residence, living alone, lower educational attainment, nonfull-time employment, weight status, non-driving status, and low MVPA among Japanese older adults. Employment status, weight status and MVPA were common correlates in both men and women. However, gender differences in the correlates of more-prolonged TV time were observed. Women's TV viewing appears to be influenced by contextual factors such as location of residence, living with others, and non-driving status. Health promotion initiatives for older adults, and particularly for older women, may be more effective if they take these attributes into account.

\section{Competing interests}

The authors declare that they have no competing interests.

\section{Authors' contribution}

$\mathrm{SI}, \mathrm{KO}$ and TSI developed study design. HK, SI and KO collected data and conducted statistical analysis. HK and SI prepared draft version of the manuscript. All authors critically revised the manuscript for important intellectual content. All authors read and approved the final manuscript.

\section{Acknowledgements}

This study was supported by the Grant-in-Aid for Scientific Research (C): 20500604 from the Japan Ministry of Education, Culture, Sports, Science and Technology. Sugiyama is supported by the National Health and Medical Research Council of Australia (NHMRC) Program funding (\#569940). Owen is supported by the Queensland Health Core Research Infrastructure grant and by the NHMRC Program Grant (\#569940) and a Senior Principal Research Fellowship (1003960). Sugiyama and Owen are supported by the Victorian Government's OIS Program. All authors have no other conflicts of interest, including related directorships, stock holdings, or contracts.

\section{Author details}

${ }^{1}$ Department of Preventive Medicine and Public Health, Tokyo Medical University, Tokyo, Japan. ${ }^{2}$ Behavioural Epidemiology Laboratory, Baker IDI Heart and Diabetes Institute, Melbourne, Australia. ${ }^{3}$ Faculty of Sport Sciences, Waseda University, Tokorozawa, Japan. ${ }^{4}$ School of Population Health, The 
University of Queensland, Brisbane, Australia. ${ }^{5}$ Melbourne School of Population Health, The University of Melbourne, Melbourne, Australia.

${ }^{6}$ School of Medicine, Monash University, Melbourne, Australia.

Received: 11 November 2012 Accepted: 5 March 2013

Published: 9 March 2013

\section{References}

1. Owen N, Healy GN, Matthews CE, Dunstan D: Too much sitting: the population health science of sedentary behavior. Exerc Sport Sci Rev 2010, 38:105-113.

2. Hamilton MT, Hamilton DG, Zderic TW: Role of low energy expenditure and sitting in obesity, metabolic syndrome, type 2 diabetes, and cardiovascular disease. Diabetes 2007, 56:2655-2667.

3. Jakes RW, Day NE, Khaw KT, Luben R, Oakes S, Welch A, Bingham S, Wareham NJ: Television viewing and low participation in vigorous recreation are independently associated with obesity and markers of cardiovascular disease risk: EPIC-Norfolk population-based study. Eur J Clin Nutr 2003, 57:1089-1096.

4. Kronenberg F, Pereira MA, Schmitz MK, Arnett DK, Evenson KR, Crapo RO, Jensen RL, Burke GL, Sholinsky P, Ellison RC, Hunt SC: Influence of leisure time physical activity and television watching on atherosclerosis risk factors in the NHLBI Family Heart Study. Atherosclerosis 2000, 153:433-443.

5. Dunstan DW, Salmon J, Owen N, Armstrong T, Zimmet PZ, Welborn TA, Cameron AJ, Dwyer T, Jolley D, Shaw JE: Associations of TV viewing and physical activity with the metabolic syndrome in Australian adults. Diabetologia 2005, 48:2254-2261.

6. Chang PC, Li TC, Wu MT, Liu CS, Li Cl, Chen CC, Lin WY, Yang SY, Lin CC Association between television viewing and the risk of metabolic syndrome in a community-based population. BMC Public Health 2008, 8:193.

7. Hamer M, Stamatakis E, Mishra GD: Television- and screen-based activity and mental well-being in adults. Am J Prev Med 2010, 38:375-380.

8. Hu FB, Leitzmann MF, Stampfer MJ, Colditz GA, Willett WC, Rimm EB: Physical activity and television watching in relation to risk for type 2 diabetes mellitus in men. Arch Intern Med 2001, 161:1542-1548.

9. Dunstan DW, Barr EL, Healy GN, Salmon J, Shaw JE, Balkau B, Magliano DJ, Cameron AJ, Zimmet PZ, Owen N: Television viewing time and mortality: the Australian Diabetes, Obesity and Lifestyle Study (AusDiab). Circulation 2010, 121:384-391.

10. Hamilton MT, Healy NG, Dunstan DW, Zderic TW, Owen N: Too little exercise and too much sitting: inactivity physiology and the need for new recommendations on sedentary behavior. Curr Cardiovasc Risk Reports 2008, 2:292-298.

11. Owen N, Sugiyama T, Eakin EE, Gardiner PA, Tremblay MS, Sallis JF: Adults' sedentary behavior determinants and interventions. Am J Prev Med 2011 41:189-196

12. Matthews CE, Chen KY, Freedson PS, Buchowski MS, Beech BM, Pate RR, Troiano RP: Amount of time spent in sedentary behaviors in the United States, 2003-2004. Am J Epidemiol 2008, 167:875-881.

13. Healy GN, Clark BK, Winkler EA, Gardiner PA, Brown WJ, Matthews CE: Measurement of adults' sedentary time in population-based studies. Am J Prev Med 2011, 41:216-227.

14. Clark BK, Sugiyama T, Healy GN, Salmon J, Dunstan DW, Shaw JE, Zimmet $\mathrm{PZ}$, Owen N: Socio-demographic correlates of prolonged television viewing time in Australian men and women: the AusDiab study. J Phys Act Health 2010, 7:595-601.

15. Gao X, Nelson ME, Tucker KL: Television viewing is associated with prevalence of metabolic syndrome in Hispanic elders. Diabetes Care 2007, 30:694-700

16. Gardiner PA, Healy GN, Eakin EG, Clark BK, Dunstan DW, Shaw JE, Zimmet $P Z$, Owen $N$ : Associations between television viewing time and overall sitting time with the metabolic syndrome in older men and women: the Australian diabetes obesity and lifestyle study. J Am Geriatr Soc 2011, 59:788-796.

17. Inoue S, Sugiyama T, Takamiya T, Oka K, Owen N, Shimomitsu T: Television viewing time is associated with overweight/obesity among older adults, independent of meeting physical activity and health guidelines. J Epidemiol 2012, 22:50-56.
18. Sugiyama T, Healy GN, Dunstan DW, Salmon J, Owen N: Is television viewing time a marker of a broader pattern of sedentary behavior? Ann Behav Med 2008, 35:245-250.

19. Burton NW, Khan A, Brown WJ, Turrell G: The association between sedentary leisure and physical activity in middle-aged adults. Br J Sports Med 2012, 46:747-752.

20. Oppert JM, Thomas F, Charles MA, Benetos A, Basdevant A, Simon C Leisure-time and occupational physical activity in relation to cardiovascular risk factors and eating habits in French adults. Public Health Nutr 2006, 9:746-754.

21. Tokuda Y, Okubo T, Ohde S, Jacobs J, Takahashi O, Omata F, Yanai H, Hinohara S, Fukui T: Assessing items on the SF-8 Japanese version for health-related quality of life: a psychometric analysis based on the nominal categories model of item response theory. Value Health 2009, 12:568-573.

22. Salmon J, Owen N, Crawford D, Bauman A, Sallis JF: Physical activity and sedentary behavior: a population-based study of barriers, enjoyment, and preference. Health Psychol 2003, 22:178-188.

23. Clark BK, Sugiyama T, Healy GN, Salmon J, Dunstan DW, Owen N: Validity and reliability of measures of television viewing time and other nonoccupational sedentary behaviour of adults: a review. Obes Rev 2009, 10:7-16.

24. Bowman SA: Television-viewing characteristics of adults: correlations to eating practices and overweight and health status. Prev Chronic Dis 2006 3:A38

25. Murase NKT, Ueda C, Inoue S, Shimomitsu T: Validity and reliability of Japanese version of international physical activity questionnaire. J Health Welfare Stat 2002, 49:1-9.

26. Lang IA, Rice NE, Wallace RB, Guralnik JM, Melzer D: Smoking cessation and transition into retirement: analyses from the English Longitudinal Study of Ageing. Age Ageing 2007, 36:638-643.

27. Brennan PL, Schutte KK, Moos RH: Retired status and older adults' 10-year drinking trajectories. J Stud Alcohol Drugs 2010, 71:165-168.

28. Slingerland AS, van Lenthe FJ, Jukema JW, Kamphuis CB, Looman C, Giskes K, Huisman M, Narayan KM, Mackenbach JP, Brug J: Aging, retirement, and changes in physical activity: prospective cohort findings from the GLOBE study. Am J Epidemiol 2007, 165:1356-1363.

29. Japan National Police Agency: The white paper on police 2010. Oita: Saiki Printing; 2010.

30. Jacobs JM, Cohen A, Hammerman-Rozenberg R, Azoulay D, Maaravi Y, Stessman J: Going outdoors daily predicts long-term functional and health benefits among ambulatory older people. J Aging Health 2008, 20:259-272

31. Johnson KM, Nelson KM, Bradley KA: Television viewing practices and obesity among women veterans. J Gen Intern Med 2006, 21(Suppl 3):S76-S81.

32. Salmon J, Bauman A, Crawford D, Timperio A, Owen N: The association between television viewing and overweight among Australian adults participating in varying levels of leisure-time physical activity. Int J Obes Relat Metab Disord 2000, 24:600-606.

33. Sugiyama T, Healy GN, Dunstan DW, Salmon J, Owen N: Joint associations of multiple leisure-time sedentary behaviours and physical activity with obesity in Australian adults. Int I Behav Nutr Phys Act 2008, 5:35.

34. Rhodes RE, Mark RS, Temmel CP: Adult sedentary behavior: a systematic review. Am J Prev Med 2012, 42:e3-e28.

35. Oka K, Shibata A: Dog ownership and health-related physical activity among Japanese adults. J Phys Act Health 2009, 6:412-418.

36. van Uffelen JG, Heesch KC, Hill RL, Brown WJ: A qualitative study of older adults' responses to sitting-time questions: do we get the information we want? BMC Public Health 2011, 11:458.

doi:10.1186/1471-2458-13-213

Cite this article as: Kikuchi et al:: Correlates of prolonged television viewing time in older Japanese men and women. BMC Public Health 2013 13:213. 